\title{
Studi Pengetahuan Masyarakat Mengenai Gulma Air Sebagai Bioindikator Pencemaran Air Di Desa Lambur Luar Kabupaten Tanjung Jabung Timur
}

\author{
Nining Nuraida ${ }^{1}$, Try Susanti ${ }^{2}$ \\ ${ }^{1,2}$ Program Studi Tadris Biologi UIN Sulthan Thaha Saifuddin Jambi \\ ${ }^{1}$ Email: Nining@uinjambi.ac.id
}

\begin{abstract}
Abstrak: Jumlah tumbuhan air disepanjang aliran sungai desa lambur luar menjadi penghambat lalu lintas perairan sehingga tumbuhan tersebut dikatakan sebagai gulma atau pengganggu bagi masyarakat. Penelitian ini bertujuan untuk mengetahui dan mendokumentasikan jenis-jenis gulma yang terdapat didesa lambur luar dan menggali pengetahuan masyarakat mengenai jenis gulma air yang ada dan pemanfaatannya. Penelitian ini dilakukan di Desa Lambur Luar Kabupaten Tanjung Jabung Timur dengan menggunakan metode Jelajah untuk mengumpulkan sampel Gulma yang ada. Pengumpulan data dilakukan dengan observasi, wawancara, dokumentasi dan studi literature, data dianalisis secara deskriptif kualitatif. Hasil penelitian menunjukkan terdapat 19 spesies dan 13 famili gulma air yaitu: Fimbristylis sp1, fimbristylis sp2, Cyperus sphacelatus Rottb, Blyxa aubertii Rich, Lindernia sp, Glinus oppositifolius (L.) Aug.DC., Melastoma malabathticum L, Nymphaea nouchali Burn.f, Ludwigia hyssopifolia (G.Don) Exell, Ludwigia repens J.R. Forst, Scoparia dulcis, Hippochaete debilis (Roxb.ex Vaucher) Ching, Panicum repens L, Oryza sativa, Persicaria hydropiper L, Monochoria vaginalis (Burm.f.) C.Presl, Borreria alata (Aubl.) DC, Borreria repens DC, dan Xyris sp. Dari 19 spesies yang ditemukan hanya 12 spesies saja masyarakat mengetahui nama gulma air tersebut, 7 spesiesnya hanya disebut sebagai rumput saja oleh masyarakat, gulma air ini tidak dimanfaatkan oleh masyarakat kebanyakan gulma dipakai untuk pakan ternak, maka peneliti memberikan edukasi kepada masyarakat bahwa sebenarnya gulma air ini bisa dipakai untuk pengobatan dan dipakai juga untuk mengetahui kualitas suatu perairan atau dijadikan sebagai indikator biologi suatu keadaan sungai dalam keadaan baik atau tidak.
\end{abstract}

\section{Kata Kunci: Studi Pengetahuan, Lambur Luar, Gulma Air}

Abstract: The number of aquatic plants along the river flow outside the village of Lambur becomes a barrier to water traffic so that these plants are classified to be weeds or a nuisance for local people. This study aims to determine and document the types of weeds found in the village of Lambur and explore locals' knowledge about the types of existing water weeds and their use. This research was conducted in the Village of Lambur Luar Tanjung Jabung Timur District by using the roaming method to collect existing Weed samples. Data collection is done by observation, interviews, 
documentation and literature studies, the data are analysed descriptive qualitative design. The results showed that there were 19 species and 13 families of water weeds, namely: Fimbristylis sp1, fimbristylis sp2, Cyperus sphacelatus Rottb, Blyxa aubertii Rich, Lindernia sp, Glinus oppositifolius (L.) Aug.DC, Melastoma malabathticum L, Nymphaea nouchali Burn, Ludwigia hyssopifolia (G.Don) Exell, Ludwigia repens JR Forst, Scoparia dulcis, Hippochaete debilis (Roxb.ex Vaucher) Ching, Panicum repens L, Oryza sativa, Persicaria hydropiper L, Monochoria vaginalis (Burm.f.) C.Presl, Borreria alata (Aubl.) DC, Borreria repens DC, and Xyris sp. Of the 19 species found, only 12 species, the locals know the name of the water weed, 7 species are only referred to as grass only by the locals, this water weed is not used by the them but mostly weeds are used for animal feed, the researchers provide education to the community that actually weed water can be used for treatment and to find out the quality of a waters or be used as an indicator of the biological condition of a river in wheteher good condition or not.

\section{Keywords: Knowledge Studies, Lambur Luar, Water Weeds}

Indonesia merupakan negara dengan wilayah perairan (sungai) yang sangat luas, dan merupakan unsur yang sangat penting bagi masyarakat yang aktivitas sehari-harinya dilakukan di perairan. Semakin bertambahnya jumlah penduduk, membuat sungai menjadi tercemar. Seperti yang dikatakan (Inggit Winarni, n.d.) dampak dari pertambahan penduduk salah satuya adalah terjadinya pencemaran lingkungan karena zat pencemar yang mengotori tanah dan air. Permasalahan pencemaran yang sering terjadi adalah pencemaran air dan sungai. Sungai yang tercemar karena limbah dapat menurunkan kadar $\mathrm{O}_{2}$, mengakibatkan organisme dalam air yang membutuhkan $\mathrm{O}_{2}$ akan terganggu dan menghambat perkembangan organisme yang ada di dalam air termasuk juga bakteri pengurai, dan akan sulit untuk menguraikan limbah secara alami, (V. Putri \& Umiyati, 2016) mengatakan bahwa pembuangan limbah ke aliran sungai dapat merubah kualitas air karena limbah buangan aktivitas dari masyarakat.

Sungai yang tercemar dapat mengganggu ekosistem yang ada di dalamnya, salah satu organisme yang terdapat di air adalah tumbuhan air, baik yang tumbuh didalam air, maupun mengapung dipermukaan, dengan pertumbuhan yang terkendali maka tumbuhan ini akan menjadi mikrohabitat bagi organisme lain, jika pertumbuhannya tidak terkendali dan mengganggu organisme lainnya maka disebut dengan gulma (Astuti \& Indriatmoko, 2018). Tumbuhan air mampu mengubah zat anorganik menjadi zat organik, melalui fotosintesis oleh karena itu dapat menghasilkan oksigen bagi organisme yang berada di dalam air (Augusta, 2015). Tumbuhan air dengan pertumbuhan yang blooming maka akan menjadi pengganggu atau biasa disebut dengan Gulma Air.

Gulma air merupakan jenis tumbuhan pengganggu di air kerena tumbuhnya yang tidak beraturan dan mampu bertahan hidup pada kondisi perairan yang baik maupun 
buruk dengan batas toleran tertentu. Gulma air dikelola dalam berbagai cara bertujuan untuk estetika, perikanan, deversikasi biologi, dan dipanen, ataupun dikendalikan secara manual, mekanis, biologi, dan herbisida seperti Anchrolein, Ametryn, Bromacil(Yernelis Sukman, 1995).

Desa Lambur Luar merupakan daerah perairan dengan penghasilan utamanya adalah pertanian dan perkebunan, aktivitas harian masyarakatpun banyak di lakukan di Air dengan menggunakan perahu untuk membawa hasil pertanian dan perkebunan dengan sungai sebagai jalur perlintasan untuk sampai kerumah. Disepanjang aliran sungai banyak tumbuh gulma, baik yang tumbuh di dalam air maupun mengapung, dengan kondisi sungai yang cukup bersih akan tetapi pertumbuhan gulma semakin banyak. Hal ini menandakan tingkat pencemaran sungai belum terlalu berat, namun bagi masyarakat sangat mengganggu aktivitas hariannya karena menghalangi perahu mereka yang akan membawa hasil pertanian dan perkebunan, untuk itu gulma air tersebut dibasmi dan dibuang saja oleh masyarakat.

Gulma yang tidak selalu merugikan, gulma air ini juga ada yang dijadikan masyarakat sebagai tanaman hias, ada juga yang dipakai sebagai pakan ternak dan untuk budidaya ikan. Namun sebenarnya gulma air yang ada disekitar masyarakat tersebut berpotensi sebagai obat, kosmetik serta dapat dijadikan sebagai Indikator Biologi pencemaran lingkungan. Dalam penelitian (Ayu, Budiwati, \& Kriswiyanti, 2014) memanfaatkan gulma air yaitu teratai untuk pengobatan kangker payudara, rematik, sakit kepala, stress, depresi membersihkan hati dan pankreas, selain itu selulosa eceng gondok dapat menghasilkan CMC (carboxymethil cellulose) yang dipakai dalam bidang farmasi, detergen tekstil, kosmetik dan pengobatan karena bisa sebagai pengental bisa dijadikan sebagai pengental, penstabil emulsi dan bahan pengikat (Pitaloka, Hidayah, Saputra, \& Mohammad Nasikin, 2015). Gulma air juga dapat dijadikan sebagai indikator biologi pencemaran air seperti yang kita ketahui bahwa tumbuhan yang berada di air dapat menjadi organisme yang membersihkan perairan (Astuti \& Indriatmoko, 2018). Tujuan dari penelitian ini adalah untuk mengetahui jenis gulma air apa saja yang terdapat didesa Lambur Luar dan menggali pengatahuan lokal masyarakat tentang jenis gulma air yang ada serta memberikan edukasi kepada masyarakat mengenai gulma air ssebagai bioindikator pencemaran air dan manfaat lain dari gulma air.

\section{METODE PENELITIAN}

Penelitian ini dilaksanakan pada bulan Juni-Agustus 2019. Penelitian ini dilaksanakan di Desa Lambur Luar Kabupaten Tanjung Jabung Timur. Metode penelitian ini dengan menggunakan metode deskriptif kualitatif (Sugiyono, 2007). Pengumpulan data dilakukan dengan studi pendahuluan dengan tujuan untuk mengetahui keadaan lokasi penelitian dengan melakukan pengamatan dan pencatatan hal-hal yang berhubungan dengan penelitian (Usman Hundaeni \& P.S Akbar, 2003) serta perkenalan dengan masyarakat yang akan menjadi narasumber.

BIOLOGI SEL (VOL 8 NO 2 EDISI JUL-DES 2019 ISSN 2252-858X/E-ISSN 2541-1225) PAGE 103 
Pengumpulan informasi dilakukan dengan wawancara semi terstruktur. Penentuan informan dalam penelitian ini dilakukan dengan purposive sampling yaitu dengan pertimbangan tertentu, dalam hal ini orang yang rumahnya paling dekat dengan aliran sungai dan banyak terdapat gulma air, informan dalam penelitian ini melibatkan 11 orang masyarakat. Penelitian dilapangan yang dilakukan yaitu pengambilan sampel dengan menggunakan metode jelajah, setelah sampel didapat kemudian diherbariumkan untuk di identifikasi di laboratorium Universitas Andalas Padang untuk mengatahui nama ilmiah jenis gulma air tersebut, kemudian mencocokkan sampel gulma air yang didapat dengan buku-buku acuan yang ada.

Data yang didapat di lapangan melalui observasi lapangan, wawancara, studi pustaka dikumpulkan dan dianalisis secara deskriptif kualitatif berupa uraian tentang deskripsi jenis gulma air yang diperoleh dan mengenai hasil pengetahuan masyarakat mengenai gulma air, serta edukasi kepada masyarakat mengenai peran gulma air sebagai bioindikator pencemaran air serta manfaat lain gulma air.

\section{HASIL DAN PEMBAHASAN}

Berdasarkan hasil identifikasi dan ekplorasi didapat 19 jenis gulma air di Desa Lambur Luar. Beberapa jenis gulma yang ditemukan sebagian ditemukan di pinggiran sungai, namun ketika air pasang gulma terebut terendam dalam air. Masyarakat tidak memanfaatkan gulma yang ada, dan gulma ini hanya di basmi saja oleh masyarakat. Berikut tabel jenis gulma air yang teridentifikasi di desa lambur luar Tabel 1.

Tabel 1. Jenis-jenis Gulam Air yang Teridentifikasi

\begin{tabular}{|c|c|c|c|}
\hline Famili & Spesies & Sinonim & Nama Lokal \\
\hline Cyperaceae & Fimbristylis $\mathrm{sp} 2$ & - & Rumput Sendum \\
\hline Cyperaceae & Fimbristylis sp1 & - & Rumput Kasuran \\
\hline Cyperaceae & Cyperus spacelatus Rottb. & - & Rumput Teki \\
\hline Hydrocharitaceae & Blyxa aubertii Rich. & - & Rumput Krisan \\
\hline Linderniaceae & Lindernia sp. & - & - \\
\hline Malluginaceae & $\begin{array}{l}\text { Glinnus oppositifolius (L) Aug } \\
\text { DC }\end{array}$ & - & - \\
\hline Melastomaceae & Melastoma malabatricum $\mathrm{L}$ & - & Keduduk \\
\hline Nymphaeceae & Nymphaea nauchali Burn. F. & $\begin{array}{l}\text { Nymphaea stella } \\
\text { Wild }\end{array}$ & Teratai Putih \\
\hline Onagraceae & $\begin{array}{l}\text { Ludwigia hyssopifolia (G.Don) } \\
\text { Exell }\end{array}$ & - & - \\
\hline Onagraceae & Ludwigia repens J.R Forst. & - & Aur-aur \\
\hline Plantaginaceae & Scoparia dulcis & - & - \\
\hline Plantaginaceae & $\begin{array}{l}\text { Hippochaete debilis (Roxb ex } \\
\text { Vaucher) CHing }\end{array}$ & $\begin{array}{l}\text { Equisetum debile } \\
\text { Roxb ex Vaucher }\end{array}$ & Rumput Jarum \\
\hline Poaceae & Panicum repens $\mathrm{L}$ & - & Lempuyangan \\
\hline Poaceae & Oryza sativa $\mathrm{L}$ & - & Padi \\
\hline Polygonaceae & Persicaria hydropiper $\mathrm{L}$ & $\begin{array}{l}\text { Polygonum } \\
\text { hydropiper L. }\end{array}$ & - \\
\hline
\end{tabular}

BIOLOGI SEL (VOL 8 NO 2 EDISI JUL-DES 2019 ISSN 2252-858X/E-ISSN 2541-1225) PAGE 104 


\begin{tabular}{|c|c|c|c|c|}
\hline Pontederiaceae & $\begin{array}{l}\text { Monochoria vaginalis (Burn f) } \\
\text { C. Presl }\end{array}$ & - & & Eceng Padi \\
\hline Rubiaceae & Spermacoce alata Aubl. & $\begin{array}{l}\text { Borrirea } \\
\text { (Aubl) DC. }\end{array}$ & alata & - \\
\hline Rubiaceae & $\begin{array}{l}\text { Spermacoce exilis (L.O Wiliams) } \\
\text { C.D. Adams Ex W.C Burger \& } \\
\text { C.M. Taylor }\end{array}$ & $\begin{array}{l}\text { Borrirea } \\
\text { DC. }\end{array}$ & repens & - \\
\hline Xyridaceae & Xyris sp & - & & Rumput Gajah \\
\hline
\end{tabular}

Spesies Gulma yang ditemukan di Sepanjang Aliran Sungai Desa lambur Luar Tanjung Jabung Timur

Hasil identifikasi terdapat 13 famili gulma air yang telah dikelompokkan dan deskripsi masing-masing gulma air tersebut: Cyperaceae dengan spesies gulma Fimbristylis sp $1 \& 2$ merupakan gulma yang habitatnya banyak terdapat di rawa-rawa, jenis gulma ini dengan rimpang yang paling pendek dan paling rendah (Bruce, 2013). Tumbuhan yang dikatakan masyarakat sebagai gulma ini sebenarnya dapat digunakan untuk mangatasi pencemaran air, tidak hanya itu dinegara india gulma ini dimanfaatkan untuk menjernihkan air akibat limbah tekstil yang dibuang ke sungai (Kadam et al., 2018). Cyperus sphacelatus Rottb merupakan jenis teki-tekian dengan habitat di daerah kering dan daerah basah seperti rawa, merupakan jenis gulma dengan petumbuhan yang sangat cepat sehingga dengan jumlah yang sangat banyak, mengganggu tumbuhan lain, dengan menyerap unsur mikro dan makro dalam tanah serta melepaskan zat alelopati sehingga menghambat perkecambahan tumbuhan lain (Kusuma, Chozin, \& Guntoro, 2017).

Hydrocharitaceae dengan spesies gulma Blyxa aubertii Rich dengan habitat di perairan dangkal, air tawar dan rawa-rawa, banyak digunakan untuk aquarium dan juga menjadi sayuran (Blyxa \& Beentje, 2017). Linderniaceae dengan spesies gulma Lindernia sp gulma air ini tumbuh di daerah perairan, gulma ini juga memiliki kemampuan menyerap zat pencemar dalam tanah dan air seperti merkuri karena memiliki toleransi terhadap logam berat (Pratiwi, Nuraini, \& Handayanto, 2016). Malluginaceae dengan spesies gulma Glinus oppositifolius (L.) Aug. DC, gulma ini hidup dipinggiran rawa, sungai, gulma ini ternyata mempunyai banyak khasiat di Thailad gulma ini dipakai untuk anti spetik dan ekspektoran (Chakraborty \& Paul, 2017), sedangkan di Indonesia masyarakat sumbawa menggunakan gulma ini sebagai obat malaria (Rahayu \& Rustiami, 2017).

Melastomaceae dengan spesies gulma Melastoma malabathricum L, atau biasa dikenal dengan sebutan keduduk, tumbuhan ini buahnya dapat dipergunkan sebagai pewarna makanan alami (Azizah \& Hartana, 2018) dan juga memiliki potensi sebagai anti bakteri (Handayani, Lambui, \& Suwastika, 2017). Nymphaeceae dengan spesies gulma Nymphaea nouchali Burn. f gulma berdaun lebar dan hidup dipermukaan air. Gulma ini dapat dijadikan sebagai indikator biologi pencemaran air dan dijadikan sebgaia tumbuhan yang dapat menyerap limbah berbahaya dengan kadar tertentu (Tayeb, 2015). 
Onagraceae dengan spesies gulma Ludwigia hyssopifolia (G.Don) Exell gulma ini digunkan untuk fitoremedisi di air, dalam penelitian yang dilakukan irawanto ini dilakukan pada taman kolam (Irawanto, 2016). Gulma Ludwigia repens J.R. Forst gulma ini di Amerika Utara dipergunakan untuk membersihkan air dan danau, sebagai sayuran, hiasan di aquarium dan juga untuk pengobatan (Öztürk, Khawar, Atar, Sancak, \& Özcan, 2004). Ludwigia repens dari hasil penelitian juga dapat dipergunakan sebagai obat penenang dan aktifitas analgesik (Uddin, Mohammed, Islam, \& Chowdhury, 2012).

Plantaginaceae dengan spesies gulma Scoparia dulcis L habitat asli Amerika Tropis tumbuh di wilayah persawahan dan ladang kering, gulma ini dapat dipergunakan sebagai Bioremediasi terhadap logam berat $(\mathrm{Cr}, \mathrm{Pb}$ dan $\mathrm{Cd})$ dengan menggunakan kultur tunas sehingga mampu menyerap logam kecuali Logam $\mathrm{Pb}$ (Djoko Santoso, Nurma Sabila, Irma Puspita Dewi, 2013). Gulma Equsetum debile Roxb ex. Vaucher biasa dikenal dengan paku ekor kuda, gulma ini dapat dimanfaatkan untuk polip, berbagai jenis kangker, hati, usus dan lambung (Sarkar et al., 2012). Poaceae dengan spesies gulma Panicum repens L gulma ini dimanfaatkan sebagai tumbuhan pelindung bagi organisme yang ada diair, seperti tempat pemijahan ikan dengan menempelkan telur-telurnya, penelitian ini dilakukan didanau Limboto (Suryani \& Sugianti, 2009). Selain sebagai tumbuhan pelindung, berdasarkan hasil penelitian (Newman, n.d.) dipakai sebagai ladang penggembalaan dan tumbuhan ini juga berpotensi sebagai pestisida alami hama. Oryza sativa L Tanaman ini terkadang memiliki pengganggu berupa hama maupun gulma, biasa hidup di tempat yang lembab dan berair, bukan merupakan tumbuhan liar melainkan tumbuhan yang sengaja ditanam, jadi tidak dapat dikatakan gulma.

Polygonaceae dengan spesies gulma Polygonum hydropiper L tumbuhan ini memiliki kandungan metablit sekunder yang banyak masyarakat cina menggunakan tumbuhan ini sebagai obat untuk menghilangkan rasa nyeri, batuk berdahak, inflamasi dengan metabolit flavonnoid dengan mengekstrak seluruh bagian tumbuhan ini (Tao, Wei, \& Hu, 2016). Pontederiaceae dengan spesies gulma Monochoria vaginalis (Burm.f) C. Presl meruakan gulma dengan pertumbuhan yang sangat cepat, namun gulma ini mampu meyerap logam berat tertentu yang mencemari air dengan menggunakan akarnya untuk menyerap polutan kemudian menyimpannya didalam batang (Y. D. Putri, Holik, Musfiroh, \& Aryanti, 2014).

Rubiaceae dengan spesies gulma Borreria alata (Aubl.) DC, gulma ini dapat dijadikan sebagai indikator kualitas air (V. Putri \& Umiyati, 2016; Rijal. M, 2016), memiliki daya adaptasi yang sangat tinggi hal ini lah yang membuat gulma ini dapat mengganggu tanaman lain. Gulma Borreria repens DC dengan habitat pinggiran sungai dan berukuran kecil, gulma ini dapat dijadikan sebagai naungan hewan air yang ada didalamnya (Wulandari, 2016). Xyridaceae dengan spesies gulma Xyris sp tumbuhan ini merupakan jenis tumbuhan tahunan dan tumbuh di daerah tropis dan subtropis dan tumbuhan ini berasal dari amerika selatan. Dalam penelitian yang dilakukan (Binur, 2010) terdapat tiga jenis baru xyiris sp yaitu xyiris nevata, xyiris pulchella, dan xyiris 
rostrata. Pemanfaatan tumbuhan ini untuk beberapa penelitian belum dikemukakan mengenai manfaatnya.

Dari 19 spesies gulma air yang teridentifikasi ada 8 spesies yang mampu mengendalikan pencemaran akibat logam berat yaitu Fimbristylis sp, Lindernia sp, Nymphaea nouchali Burn.f, Ludwigia hyssopifolia (G.Don) Exell, Ludwigia repens, Scoparia dulcis L, Monochoria vaginalis (Burm.f.) C.Presl dan Borreria alata (Aubl.) DC selebihnya, gulma yang lain ada yang dimanfaatkan dan ada yang tidak dimanfaatkan oleh masyarakat, dan hanya dianggap pengganggu saja.

\section{Pengetahuan Lokal Masyarakat Mengenai Gulma Air yang Berperan Sebagai Bioindikator Pencemaran Air}

Hasil penggalian pengetahuan masyarakat Desa Lambur Luar Tanjung Jabung timur mengenai gulma air yang terdapat disekitarnya, sebagian besar masyarakat hanya mengenali beberapa jenis gulma air saja beserta penyebutan nama daerah gulma air tersebut. Hasil penggalian mengenai pemanfaatan gulma air, tidak banyak yang memanfaatkan, hanya beberapa jenis saja yang mereka manfaatkan untuk kesehariannya. Masyarakat cenderung menganggap itu hanya sebagai gangguan dan merusak sungai dan mengotori sungai. Akan tetapi sebenarnya gulma air ini banyak sekali manfaatnya. Gulma air ini sebenarnya adalah tumbuhan yang terdapat di air, jika tumbuh dengan normal maka akan terjadinya keseimbangan ekosistem diair namun dengan pertumbuhan yang terlalu banyak tumbuhan ini menjadi gulma dan mengganggu (Astuti \& Indriatmoko, 2018), karena di Lambur luar, pertumbuhan gulma air yang tidak terkendali membuat masyarakat menganggap ini sebagai pengganggu dan gulma ini dibuang saja tanpa mengetahui sebenarnya banyak manfaat dari gulma yang ada disekitarnya.

Peneliti memberikan edukasi kepada masyarakat mengenai manfaat dari gulma yang ada, salah satu manfaatnya adalah kemampuan beberapa gulma yang ada sebagai Bioindikator pencemaran air, bahkan juga beberapa jenis gulma dapat dijadikan sebagai tumbuhan pembersih lahan yang sudah tercemar. Monochoria vagilanis atau eceng misalnya merupakan tumbuhan yang dianggap paling mengganggu karena jumlah nya yang banyak dan pertumbuhan yang sangat cepat, bisa terjadi blooming pada pertumbuhannya. Eceng ini mampu bertahan hidup pada kondisi perairan yang baik maupun kondisi air yang terkontaminasi oleh zat pencemar sehingga tumbuhan ini lah yang sangat baik untuk mengolah air yang tercemar limbah (Aniningrum \& Pramushinta, 2015). Selain itu tumbuhan yang terdapat disekitar perairan juga bisa memberikan manfaat bagi organisme yang ada didalamnya, seperti untuk tempat berteduhnya ikan, pemijahan ikan, nutrisi bagi keong dan juga dibutuhkan oleh organisme untuk menghasilkan oksigen. Tumbuhan air sangat efektif untuk meningkatkan kadar oksigen dalam air melalui proses fotosintesis (Puspitaningrum, Izzati, \& Haryanti, 2012). 


\section{KESIMPULAN}

Hasil penelitian dan identifikasi didapatkan 19 jenis gulma air yang terdapat didesa Lambur Luar Kabupaten Tanjung Jabung Timur, yaitu Fimbristylis sp 2, Fimbristylis sp 1, Cyperus sphacelatus Rottb, Lindernia sp, Melastoma malabathricum L, Nymphaea nouchali Burn.f, Ludwigia hyssopifolia (G.Don) Exell, Ludwigia repens J.R. Forst, Equisetum debile Roxb ex Vaucher, Panicum repens L, Oryza sativa L, Polygonum hydropiper L, Monochoria vaginalis (Burn.f.) C. Presl, Borreria alata (Aubl.) DC, Borreria repens DC, dan Xyris sp. Tidak banyak masyarakat mengetahui nama gulma air yang ada, ,gulma yang dapat dijadikan sebagai bioindikator pencemaran air hanya 8 jenis saja, dan gulma yang paling banyak adalah Monochoria vaginalis (Burn.f.) C. Presl dan gulma ini juga sering dimanfaatkan masyarakat untuk kesehariannya seperti pakan ternak dan untuk menjernihkan air kolam mereka.

\section{DAFTAR PUSTAKA}

Aniningrum, \& Pramushinta. (2015). Penghilangan Limbah Pestisida Tebukonazol dengan Sistem Fitoremediasi Menggunakan Eceng Gondok (Echornia Crassipes). 8(September), 32-35.

Astuti, L. P., \& Indriatmoko, I. (2018). Kemampuan Beberapa Tumbuhan Air dalam Menurunkan Pencemaran Bahan Organik dan Fosfat untuk Memperbaiki Kualitas $\begin{array}{llll}\text { Air. Jurnal Teknologi Lingkungan, } & 183 .\end{array}$ https://doi.org/10.29122/jtl.v19i2.2063

Augusta, T. S. (2015). Identifikasi Jenis dan Analisa Vegetasi Tumbuhan Air. Jurnal Ilmu Hewani Tropika, 4(1), 1-5.

Ayu, G., Budiwati, N., \& Kriswiyanti, E. (2014). Manfaat tanaman teratai. (1).

Azizah, E., \& Hartana, A. (2018). PEMANFAATAN DAUN HARENDONG (Melastoma malabathricum) SEBAGAI PEWARNA ALAMI UNTUK KAIN KATUN. Dinamika Kerajinan Dan Batik: Majalah Ilmiah, 35(1), 1. https://doi.org/10.22322/dkb.v35i1.3490

Binur, R. (2010). Komposisi Jenis Ikan Air Tawar di Daerah Lahan Basah Kaliki, Merauke Papua. Jurnal Iktiologi Indonesia, 10(2), 165-178.

Blyxa, R. F., \& Beentje, A. (2017). Blyxa aubertii,. 8235.

Bruce, 2011. (2013). A Guide Book to Invasive Alien Plant Species in Indonesia. In P. D. T. Partomihardjo, D. S. Tjitrosoedirdjo, \& Dr. Sunaryo (Eds.), Journal of Chemical Information and Modeling (Vol. 53). https://doi.org/10.1017/CBO9781107415324.004

Chakraborty, T., \& Paul, S. (2017). <em>Glinus oppositifolius</em> (L.) Aug. DC.: A Repository of Medicinal Potentiality. International Journal of Phytomedicine, 9(4), 543. https://doi.org/10.5138/09750185.2164

Djoko Santoso, Nurma Sabila, Irma Puspita Dewi, L. N. A. (2013). Lindernia ciliata AND THE EFFORT OF BIOREMEDIATION FOR HEAVY-METAL PB , CR , CD 
KULTUR TUNAS Scoparia dulcis, lindernia anagalis, Lindernia ciliata DAN. 18(January), 29-34.

Handayani, M., Lambui, O., \& Suwastika, I. N. (2017). Potensi Tumbuhan Melastoma malabathricum L. Sebagai Bahan Antibakteri Salmonellosis. Natural Science: Journal of Science and Technology, 6(2), 165-174. https://doi.org/10.22487/25411969.2017.v6.i2.8665

Inggit Winarni. (n.d.). Peran Mikroba sebagai Biomonitoring Kualitas Perairan Tawar pada Beberapa Situ. 143-176.

Irawanto, R. (2016). Purwodadi sebagai Taman Kolam Fitoremediasi. (1), 1-6.

Kadam, S. K., Chandanshive, V. V., Rane, N. R., Patil, S. M., Gholave, A. R., Khandare, R. V., ... Govindwar, S. P. (2018). Phytobeds with Fimbristylis dichotoma and Ammannia baccifera for treatment of real textile effluent: An in situ treatment, anatomical studies and toxicity evaluation. Environmental Research, 160(September 2017), 1-11. https://doi.org/10.1016/j.envres.2017.09.009

Kusuma, A. V. C., Chozin, M. A., \& Guntoro, D. D. (2017). Senyawa Fenol dari Tajuk dan Umbi Teki (Cyperus rotundus L.) pada Berbagai Umur Pertumbuhan serta Pengaruhnya terhadap Perkecambahan Gulma Berdaun Lebar. Jurnal Agronomi Indonesia (Indonesian Journal of Agronomy), 45(1), 100. https://doi.org/10.24831/jai.v45i1.11842

Newman, S. D. (n.d.). Torpedo Grass.

Öztürk, M., Khawar, K. M., Atar, H. H., Sancak, C., \& Özcan, S. (2004). In vitro micropropagation of the aquarium plant Ludwigia repens. Asia-Pacific Journal of Molecular Biology and Biotechnology, 12(1-2), 21-25.

Pitaloka, A. B., Hidayah, N. A., Saputra, A. H., \& Mohammad Nasikin. (2015). PEMBUATAN CMC DARI SELULOSA ECENG GONDOK DENGAN MEDIA REAKSI CAMPURAN LARUTAN ISOPROPANOL-ISOBUTANOL UNTUK MENDAPATKAN VISKOSITAS DAN 1 Jurusan Teknik Kimia, Fakultas Teknik, Universitas Sultan Ageng Tirtayasa, Cilegon, Banten, 2 Departemen Teknik Ki. Jurnal Integrasi Proses, 5(2), 108-114.

Pratiwi, R. S., Nuraini, Y., \& Handayanto, E. (2016). Pemanfaatan Tumbuhan Liar Lindernia crustacea dalam Fitoremediasi Tanah Tercemar Merkuri Limbah Tambang Emas Skala Kecil. Jurnal Tanah Dan Sumberdaya Lahan, 3(1), 261-267. Retrieved from https://docs.google.com/viewerng/viewer?url=https://jtsl.ub.ac.id/index.php/jtsl/art icle/viewFile/137/147

Puspitaningrum, M., Izzati, M., \& Haryanti, S. (2012). Produksi dan Konsumsi Oksigen Terlarut Oleh Beberapa Tumbuhan Air. Buletin Anatomi Dan Fisiologi, 10(Maret), 47-55.

Putri, V., \& Umiyati, U. (2016). Hubungan kualitas air tercemar dengan keragaman gulma air di Daerah Aliran Sungai Cikeruh dan Cikapundung Provinsi Jawa Barat

BIOLOGI SEL (VOL 8 NO 2 EDISI JUL-DES 2019 ISSN 2252-858X/E-ISSN 2541-1225) PAGE 109 
The relationship between contaminated water quality and weed diversity in Cikeruh and Cikapundung rivers. 15(3), 194-201.

Putri, Y. D., Holik, H. A., Musfiroh, I., \& Aryanti, A. D. (2014). Utilization of Ponteridaceae as Phytoremediation Agent in Chrome Waste Treatment. Indonesian Journal of Pharmaceutical Science and Technology, 1(1), 20-25. https://doi.org/10.15416/ijpst.v1i1.7510

Rahayu, M., \& Rustiami, H. (2017). Etnobotani Masyarakat Samawa Pulau Sumbawa. Scripta Biologica, 4(4), 235. https://doi.org/10.20884/1.sb.2017.4.4.605

RIJAL, M. (2016). KUALITAS AIR SUNGAI ARBES DAN POTENSI TUMBUHAN AIR SEBAGAI AGEN FITOREMEDIATOR DALAM PENGEMBANGAN BUKU PENUNJANG PENGETAHUAN LINGKUNGAN BERBASIS RISET DI IAIN AMBON. DISERTASI dan TESIS Program Pascasarjana UM.

Sarkar, B., Abu Raihan, S. M., Sultana, N., Rahman, R., Islam, M. E., Ahmed, S., \& Akter, S. (2012). Cytotoxic, antibacterial and free radical scavenging activity studies of the solvent extracts of aerial stems of Equisetum debile Roxb. International Journal of Chemical Sciences, 10(1), 19-26.

Sugiyono. (2007). Memahami Penelitian Kualitatif. Bandung: Alfa Beta.

Suryani, A., \& Sugianti, Y. (2009). Manfaat Dan Permasalahannya. 151-154.

Tao, J., Wei, Y., \& Hu, T. (2016). Flavonoids of Polygonum hydropiper L . attenuates lipopolysaccharide-induced inflammatory injury via suppressing phosphorylation in MAPKs pathways. 1-15. https://doi.org/10.1186/s12906-016-1001-8

Tayeb, W. (2015). Kemampuan Penyerapan Teratai dalam menurunkan kadar Amonia (NH3) untuk air limbah RSUD.

Uddin, M. E., Mohammed, A., Islam, T., \& Chowdhury, A. U. (2012). Sedative and analgesic activities of Ludwigia repens. 2(2), 202-211.

Usman Hundaeni, \& P.S Akbar. (2003). Metodologi Penelitian Sosial. Jakarta: Bumi Aksara.

Wulandari, A. (2016). Vol. 1, No. 2, November 2016. 1(2), 22-30.

Yernelis Sukman. (1995). Gulma dan Teknik Pengendaliannya (Cetakan II). Jakarta: Pt. Raja Grafindo. 